\title{
OPTIMALISASI PIPA BAJA DENGAN MENGGUNAKAN PERAMALAN DAN PENGENDALIAN PERSEDIAAN BAHAN BAKU DI PT. ANGKASA RAYA STEEL
}

\author{
Sofiya Nurriyanti \\ Program Studi Teknik Industri, Universitas Qomaruddin Gresik \\ Email: sofiyanurriyanti20@gmail.com
}

\begin{abstract}
ABSTRAK
PT. Angkasa Raya Steel adalah perusahaan manufaktur yang bergerak pada industri pembuatan pipa baja. Pipa baja yang diproduksi oleh perusahaan langsung dijual ke pada supliyer-supliyer terpercaya. Dalam produksinya perusahaan menghasilkan empat jenis pipa baja. Bahan baku juga langsung di datangkan dari supplier PT. Java Pasifik dan PT. Inti Sumber. Bahan baku pipa baja yang digunakan oleh PT. Angkasa Raya Steel bernama Coil. Namun seringkali, perusahaan mengalami kekurangan stok bahan baku dan perusahaan tidak memiliki safety stock. Kurangnya stock persediaan dari gudang mengakibatkan perusahaan tidak dapat melakukan produksi sehingga mengalami kelambatan dalam mengirim produk jadi ke konsumen. Oleh karena itu, dengan adanya permintaan produk dari costumer perusahaan memerlukan pengendalian persediaan bahan baku, agar persediaan bahan baku dan permintaan produk dari costumer stabil. Salah satu metode yang digunakan untuk pengendalian persediaan bahan baku adalah metode "Economic Order Quantity" (EOQ). September 2018 metode exponential smoothing 3 bulan dipilih sebagai acuan dalam persediaan bahan baku dikarenakan mempunyai nilai error terkecil dengan nilai 406164757,13. Berdasarkan hasil pengendalian persediaan dengan metode $E O Q$ dapat diketahui dengan menggunaan metode $E O Q$, jika PT. Angkasaaya Steel menggunakan metode $E O Q$ dapat menghemat biaya sebesar Rp 31.261.22.955.000 per Tahun.
\end{abstract}

Kata kunci: Forecasting, EOQ, Pengendalian, Persediaan.

\section{Pendahuluan}

PT. Angkasa Raya Steel merupakan perusahaan perseroan terbatas yang bergerak dalam bidang industri pembuatan pipa baja yang berbahan baku coil dan terdiri dari beberapa saham. Perusahaan ini menjadi perusahaan industri besi lokal yang terpercaya dalam mensupply proyek-proyek pembangunan untuk memenuhi kebutuhan customer di seluruh Indonesia. Bahan baku juga langsung di datangkan dari supplier PT. Java Pasifik dan PT. Inti Sumber. Bahan baku pipa baja yang digunakan oleh PT. Angkasa Raya Steel bernama Coil. PT. Angkasa Raya Steel beroperasi pada bulan Juni 2015, seiring dengan tingginya permintaan konsumen, maka perusahaan meningkatkan produktivitas dan memiliki beberapa karyawan dan setiap karyawan memiliki job description masing-masing, untuk bagian produksi hingga proses packaging. Akan tetatpi setiap perusahaan juga mengalami kekurangan stock bahan baku sehingga perusahaan tidak memilik safety stock salah satunya di perusahaan PT. Angkasa Raya Steel. Oleh karena itu dengan adanya keterlambatan dalam mengirim barang ke costumer perusahaan juga memerlukan pengendalian persediaan bahan baku agar persediaan dan permintaan produk dari costumer dapat berjalan baik dan stabil. Salah satu metode yang digunakan untuk pengendalian persediaan bahan baku adalah metode Economy Order Quantity (EOQ).

Suatu teknik pengendalian persediaan yang menentukan seberapa banyak kuantitas barang yang harus dipesan dan kapan barang itu dipesan untuk mencapai nilai target ekonomis dengan menghitung nilai total biaya persediaan bahan baku tahunan [1]. Apabila persediaan bahan baku yang optimal perusahaan juga mampu menentukan seberapa besar persediaan bahan baku yang sesuai agar tidak menimbulkan pemborosan pada biaya [2]. PT. Angkasa Raya Steel adalah perusahaan manufaktur yang bergerak pada industri pembuatan pipa baja yang berlokasi di sebuah kawasan industri di Jl. Raya Manyarejo. Pipa baja yang diproduksi oleh perusahaan langsung dijual ke pada supliyersupliyer terpercaya. Dalam produksinya perusahaan menghasilkan empat jenis pipa baja. Bahan baku juga langsung di datangkan dari supplier PT. Java Pasifik dan PT. Inti Sumber. Bahan baku pipa baja yang digunakan oleh PT. Angkasa Raya Steel bernama Coil. Namun seringkali, perusahaan mengalami kekurangan stok bahan baku dan perusahaan tidak memiliki safety stock. Kurangnya stock persediaan dari gudang mengakibatkan perusahaan tidak dapat melakukan produksi sehingga mengalami kelambatan dalam mengirim produk jadi ke konsumen. Oleh karena 


\section{KAIZEN : MANAGEMENT SYSTEMS \& INDUSTRIAL ENGINEERING JOURNAL VOL. 2 NO. 1 TEKNIK INDUSTRI UNIVERSITAS PGRI MADIUN}

itu, dengan adanya permintaan produk dari costumer perusahaan memerlukan pengendalian persediaan bahan baku, agar persediaan bahan baku dan permintaan produk dari costumer stabil.

Salah satu metode yang digunakan untuk pengendalian persediaan bahan baku adalah metode "Economic Order Quantity" (EOQ). Metode EOQ adalah metode menghitung persediaan optimal dengan cara memasukkan biaya pemesanan dan penyimpanan [3]. Perencanaan model EOQ dalam sebuah perusahaan dapat membantu perusahaan meminimalisasi tingkat persediaan, biaya, dan tingkat terjadinya out of stock. Selain itu dengan menggunakan model EOQ, perusahaan dapat mengurangi biaya penyimpanan, penghematan ruang, serta dapat menyelesaikan masalah-masalah yang timbul dari adanya penumpukan persediaan bahan. Tujuan dalam penelitian ini untuk mengetahui hasil perhitungan metode peramalan dengan menggunakan tiga metode untuk mencari jumlah SEE terkecil berdasarkan data permintaan yang ada dan menentukan perhitungan persediaan bahan baku pipa baja dengan menggunakan metode EOQ. Sehingga hal ini dilakukan untuk mengantisipasi kekurangan bahan, terlambatnya pengiriman ataupun gagalnya pengiriman barang yang telah disediakan [4].

\section{Metode Penelitian}

Jenis penelitian yang digunakan dalam penelitian ini adalah kualitatif dan kuantitatif yang merupakan penjelasan dari karateristik suatu fenomena yang diteliti dalam suatu situasi. Penelitian kualitatif ini juga memecahkan suatu masalah yang yang sebagaimana adanya penelitian pada saat akan dilaksanakan. Sedangkan pada analisis data ini dapat juga menentukan banyaknya kebutuhan bahan baku pipa baja selama 12 periode ke depan atau 1 tahun, dan dapat menghitun seberapa banyak persediaan bahan baku yang optimal dengan menggunakan EOQ.

1. $\quad$ Metode Deret Waktu (Time series)

Metode peramalan yang berdasarkan prakiraan dan peramalan dengan menggunakan data masa lalu dengan cara meramalkan untuk masa depan sesuai permintaan dan aktual produk yang ada atau berdasarkan historis [5].

2. Pola Data

Prakiraan atau peramalan permintaan suatu barang dan jasa dengan mempertimbangkan jenis pola data yang terbentuk yang dapat diketahui dari hasil peramalan dan paling tepat digunakan [6]. Terdapat empat pola yang dapat dibedakan antara lain Pola Trend (T), Pola Musiman atau seasonal (S), Pola Siklus atau Cycle (C), Pola Acak atau Random (R).

3. $\quad$ Metode Rata-Rata Bergerak

Pada metode rata rata bergerak ini terdapat beberapan metode yang dilakukan dalam peramalan antara lain metode weighted moving average, yang merupakan metode peramalan yang dilakukan dengan cara memberikan nilai bobot pada data data periode yang baru daripada bobot periode yang sebelumnya. Selanjutnya metode exponential smoothing merupakan metode peramalan pergerakan rata-rata bobot dengan mengulang perhitungan secara terus menerus menggunakan data terbaru sebagai dasar dengan diberi bobot atau penghalusan konstan $(\alpha)$, yang jumlahnya lebih besar dari atau sama dengan 0 dan kurang dari sama dengan 1. Penghalusan konstan $(\alpha)$, umumnya dalam kisaran 0.1 hingga 0.5 [7]. Metode moving average merupakan metode peramalan yang menggunakan ratarata dari data actual pada periode sebelumnya untuk meramalkan pada periode selanjutnya

4. Ketepatan Peramalan

Ketepatan peramalan merupakan suatu cara untuk mengukur kesalahan peramalan dengan melihat kesesuaian antara data yang sudah ada dengan data peramalan.

Kesalahan Peramalan = nilai aktual - Nilai Peramalan

Et $\quad=\mathrm{At}-\mathrm{Ft}$

Terdapat tiga cara perhitungan yang digunakan untuk menghitung kesalahan peramalan yaitu Mean Absolute Deviation (MAD), Mean Squared Error (MSE), Mean Absolute Percent Error (MAPE).

$\mathrm{MAD}=\frac{\sum(\mathrm{At}-\mathrm{Ft})}{\mathrm{n}}$

Dimana :

At = nilai actual yang sebenarnya pada periode $\mathrm{t}$

$\mathrm{Ft} \quad=$ Nilai peramalan pada periode- $\mathrm{t}$

$\mathrm{N}=$ Jumlah periode peramalan yang digunakan

MAPE $=\frac{\sum A t-F t}{n} \times 100$

Dimana:

At = nilai actual yang sebenarnya pada periode $\mathrm{t}$

$\mathrm{Ft} \quad=$ Nilai peramalan pada periode- $\mathrm{t}$

$\mathrm{N}=$ Jumlah periode peramalan yang digunakan
MSE $=\frac{\sum(\mathrm{At}-\mathrm{Ft})^{2}}{\mathrm{n}}$

Dimana :

At = nilai aktual yang sebenarnya pada periode $\mathrm{t}$

Ft $\quad=$ Nilai peramalan pada periode- $t$

$\mathrm{N} \quad=$ Jumlah periode peramalan yang digunakan

Copyright (C) 2019, Kaizen : Management Systems \& Industrial Engineering Journal ISSN 15222-96806 (print), ISSN 155222-95973 (online) 


\section{KAIZEN : MANAGEMENT SYSTEMS \& INDUSTRIAL ENGINEERING JOURNAL VOL. 2 NO. 1 TEKNIK INDUSTRI UNIVERSITAS PGRI MADIUN}

5. $\quad$ Konsep Economic Order Quantity (EOQ)

Terdapat beberapa asumsi dalam metode EOQ antara lain : Jumlah pembelian tetap, Lead time konstan, Barang yang dipesan selalu tersedia, Tidak ada diskon, Biaya melakukan pemesanan dan biaya menyimpan persediaan merupakan biaya variable dalam waktu tertentu, Pemesanan dilakukan pada waktu yang tepat untuk menghindari stock out. Pemesanan secara optimal EOQ dan frekuensi pemesanan adalah sebagai berikut :

$\mathrm{EOQ}=\frac{\sqrt{2 \mathrm{Ds}}}{\mathrm{H}}$

Keterangan :

$\begin{array}{ll}\mathrm{EOQ} & =\text { Kuantitas optimal } \\ \mathrm{D} & =\text { Permintaan } \\ \mathrm{S} & =\text { Biaya pemesanan } \\ \mathrm{H} & =\text { Biaya penyimpanan }\end{array}$

$\mathrm{Cr}=\frac{\mathrm{D}}{\mathrm{Q}}(\mathrm{Co})$

Keterangan :

$\mathrm{Cr} \quad=$ Biaya pemesanan kembali

$\mathrm{D} \quad=$ Total kebutuhan bahan baku

Q $\quad=$ Kuantitas dalam setiap kali pemesanan

Co $\quad=$ Biaya untuk setiap kali pemesanan

\section{Hasil dan Pembahasan}

Berdasarkan hasil penelitian yang telah dilakukan pada PT. Angkasa Raya Steel didapatkan bahwa pemesanan bahan baku belum optimal selama 1 tahun. Data permintaan pada pipa baja ini didapatkan berdasarkan pada tahun 20172018 yang ditunjukkan pada Tabel 1. Dibawah ini

Tabel 1. Data Permintaan Produk Pipa Baja Galvanis

\begin{tabular}{|c|c|c|}
\hline No & Bulan & Permintaan \\
\hline 1 & September 2017 & 87857 \\
\hline 2 & Oktober 2017 & 93457 \\
\hline 3 & November 2017 & 70735 \\
\hline 4 & Desember 2017 & 69015 \\
\hline 5 & Januari 2018 & 119342 \\
\hline 6 & Februari 2018 & 61608 \\
\hline 7 & Maret 2018 & 83468 \\
\hline 8 & April 2018 & 62738 \\
\hline 9 & Mei 2018 & 78498 \\
\hline 10 & Juni 2018 & 79038 \\
\hline 11 & Juli 2018 & 91786 \\
\hline 12 & Agustus 2018 & 92458 \\
\hline
\end{tabular}

Berdasarkan Tabel 1. diatas tahapan selanjutnya adalah perhitungan permintaan peramalan dari ke 3 metode forecasting dan menentukan penggunaan biaya bahan baku (EOQ) Economic Order Quantity. Hasil dari Tabel 1. maka dilakukan perhitungan moving average, weighted moving average dan exsponential smoothing. Perhtiungan tersebut maka diketahui nilai error dari masing-masing metode dengan mengunakan MAD, MSE dan MAPE.

\section{Moving Average}

Perhitungan moving average ini menggunakan 3 bulanan untuk meramalakan produk pipa baja. Adapun perhitungan tersebut akan dijelaskan pada Tabel 2. di bawah ini :

Tabel 2. Hasil Peramalan Moving Average 3 Bulanan

\begin{tabular}{|c|l|l|l|c|c|c|c|}
\hline No & Bulan & Permintaan & $\begin{array}{c}\text { Forecasting } \\
\text { Moving } \\
\text { Average }\end{array}$ & No & Bulan & Permintaan & $\begin{array}{c}\text { Forecasting } \\
\begin{array}{c}\text { Moving } \\
\text { Average }\end{array}\end{array}$ \\
\hline 1 & September 2017 & 87857 & - & 7 & Maret 2018 & 83468 & 83468 \\
\hline 2 & Oktober 2017 & 93457 & - & 8 & April 2018 & 62738 & 62738 \\
\hline 3 & November 2017 & 70735 & - & 9 & Mei 2018 & 78498 & 78498 \\
\hline 4 & Desember 2017 & 69015 & 84016,33 & 10 & Juni 2018 & 79038 & 79038 \\
\hline 5 & Januari 2018 & 119342 & 77735,66 & 11 & Juli 2018 & 91786 & 91786 \\
\hline 6 & Februari 2018 & 61608 & 86364 & \multicolumn{7}{|c|}{ Agustus 2018 } & 92458 & 92458 \\
\hline
\end{tabular}




\section{KAIZEN : MANAGEMENT SYSTEMS \& INDUSTRIAL ENGINEERING JOURNAL VOL. 2 NO. 1 TEKNIK INDUSTRI UNIVERSITAS PGRI MADIUN}

Adapun berdasarkan nilai forecasting diatas perhitungan dari metode moving average akan dijelaskan pada berikut ini :

$\mathrm{Ft}=\frac{\sum \text { Permintaan dalam periode } \mathrm{n} \text { sebelumnya }}{}$

$\mathrm{Ft}=\frac{(\mathrm{At}-1+\mathrm{At}-2+\cdots \times+\mathrm{n}}{\mathrm{n}}$

Dimana :

Ft = nilai peramalan untuk periode berikutnya

At-1 = nilai permintaan actual periode sebelumnya

$\mathrm{n} \quad=$ jumlah periode yang digunakan

Diketahui :
a) Bulan Desember 2017
$=97857+93457+7073$
$=84016,33$
b) Bulan Januari 2018
c) Bulan Februari 2018
$=\frac{93457+70725+69015}{=77735,66}$
$=\quad \begin{gathered}\text { a bulan } \\ \text { rora } 5+69015+119342\end{gathered}$
$=86364$
d) Bulan Maret 2018
e) Bulan April 2018
f) Bulan Mei 2018
g) Bulan Juni 2018
h) Bulan Juli 2018
i) Bulan Agustus 2018
$=\underline{\text { 69015 }+119342+61608}$
$=83321,67$
a bulan
$=\frac{119342+61608+83469}{=88139,33}$
$=\frac{61608+83468+62739}{=69271,33}$
$\begin{array}{ll}=\frac{\text { a bulan }}{93468+62798+78499} & =74901,34\end{array}$

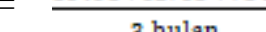
$=14901,34$
$=\frac{62738+78498+79038}{=}=73424,66$
$=\frac{78498+79038+91786}{=83107,34}$
j) Bulan September 2018
$=\frac{79038+91786+92458}{362}$
$=87760,67$

Berdasarkan hitungan ramalan menggunakan moving average 3 bulanan pada bulan September (no 13) terjadi permintaan sebesar 87760,67 produk pipa baja, permintaan tersebut akan menjadi perhitungan dalam pengolahan data persediaan bahan baku perhitungan Economic Order Quantity (EOQ).

2. Weighted Moving Average

Perhitungan weighted moving average ini menggunakan 3 pembobotan untuk meramalakan produk jadi pipa baja galvanis. Adapun perhitungan tersebut akan dijelaskan pada Tabel 3 di bawah ini :

Tabel 3. Hasil Peramalan Weighted Moving Average

\begin{tabular}{|c|l|c|c|c|c|c|c|}
\hline No & Bulan & Permintaan & $\begin{array}{c}\text { Forecasting } \\
\text { Weghted } \\
\text { Moving } \\
\text { Average }\end{array}$ & No & Bulan & Permintaan & $\begin{array}{c}\text { Forecasting } \\
\text { Weghted } \\
\text { Moving } \\
\text { Average }\end{array}$ \\
\hline 1 & September 2017 & 87857 & - & 7 & Maret 2018 & 83468 & 80852,66 \\
\hline 2 & Oktober 2017 & 93457 & - & 8 & April 2018 & 62738 & 76181,33 \\
\hline 3 & November 2017 & 70735 & - & 9 & Mei 2018 & 78498 & 69648 \\
\hline 4 & Desember 2017 & 69015 & 78309 & 10 & Juni 2018 & 79038 & 73244,66 \\
\hline 5 & Januari 2018 & 119342 & 69588,34 & 11 & Juli 2018 & 91786 & 78858 \\
\hline 6 & Februari 2018 & 61608 & 102566,3 & 12 & Agustus 2018 & 92458 & 87536,67 \\
\hline
\end{tabular}

Adapun berdasarkan nilai forecasting diatas perhitungan dari metode weighted moving average pembobotan 3 akan dijelaskan pada berikut ini :

$\begin{aligned} \mathrm{Ft} & =\frac{\sum((\text { Bobot untuk periode n }) \text { Permintaan dalam periode } \mathrm{n})}{\sum \text { Bobot }} \\ \mathrm{Ft} & =\frac{\text { W1At }-1+\text { W2At }-2+\text { W3At }-3+\ldots \ldots+\text { WnAt }-\mathrm{n}}{\sum \mathrm{Wi}}\end{aligned}$

Copyright (C) 2019, Kaizen : Management Systems \& Industrial Engineering Journal ISSN 15222-96806 (print), ISSN 155222-95973 (online) 
Dimana :

$\mathrm{Ft} \quad=$ Nilai peramalan untuk periode berikutnya

$\mathrm{Wi} \quad=$ nilai bobot

$\mathrm{t}-1=$ nilai permintaan aktual periode sebelumnya

$\mathrm{n} \quad=$ jumlah periode yang digunakan

a) Bulan Desember $2017=(2 \times 70735)+(1 \times 93457) / 3=78309$

b) Bulan Januari $2018=(2 \times 69015)+(1 \times 70735) / 3=69588,34$

c) Bulan Februari $2018=(2 \times 119342)+(1 \times 69015) / 3=102566,3$

d) Bulan Maret $2018=(2 \times 61608)+(1 \times 119342) / 3=80852,66$

e) Bulan April $2018=(2 \times 83468)+(1 \times 61608) / 3=76181,33$

f) Bulan Mei $2018=(2 \times 62738)+(1 \times 83468) / 3=69648$

g) Bulan Juni $2018=(2 \times 78498)+(1 \times 62738) / 3=73244,66$

h) Bulan Juli $2018=(2 \times 79038)+(1 \times 78498) / 3=78858$

i) Bulan Agustus $2018=(2 \times 91786)+(1 \times 79038) / 3=87536,67$

j) Bulan September $2018=(2 \times 92458)+(1 \times 91786) / 3=92234$

Berdasarkan hitungan ramalan menggunakan weighted moving average pembobotan 3 pada bulan September (no 13) terjadi permintaan sebesar $\mathbf{9 2 2 3 4}$ produk pipa baja, permintaan tersebut akan menjadi perhitungan dalam pengolahan data persediaan bahan baku perhitungan EOQ.

3. Exsponential Smoothing

Perhitungan exponential smoothing ini menggunakan alpha sebesar 0,30 untuk meramalakan produk jadi pipa baja galvanis. Adapun perhitungan tersebut akan dijelaskan pada Tabel 4. di bawah ini :

Tabel 4. Hasil Peramalan Exponential Smoothing Alpha sebesar 0,30

\begin{tabular}{|c|c|c|c|c|c|c|c|}
\hline No & Bulan & Permintaan & \begin{tabular}{|c|} 
Exponential \\
Smoothing \\
\end{tabular} & No & Bulan & Permintaan & \begin{tabular}{|c|} 
Exponential \\
Smoothing \\
\end{tabular} \\
\hline 1 & September 2017 & 87857 & - & 7 & Maret 2018 & 83468 & 77951,53 \\
\hline 2 & Oktober 2017 & 93457 & - & 8 & April 2018 & 62738 & 79606,47 \\
\hline 3 & November 2017 & 70735 & - & 9 & Mei 2018 & 78498 & 74545,93 \\
\hline 4 & Desember 2017 & 69015 & 70735 & 10 & Juni 2018 & 79038 & 75731,55 \\
\hline 5 & Januari 2018 & 119342 & 70219 & 11 & Juli 2018 & 91786 & 76723,49 \\
\hline 6 & Februari 2018 & 61608 & 84955,9 & 12 & Agustus 2018 & 92458 & 81242,24 \\
\hline
\end{tabular}

Adapun berdasarkan nilai forecasting diatas perhitungan dari metode exponential smoothing alpha sebesar 0,30 akan dijelaskan pada berikut ini :

$\mathrm{Ft}=$ Peramalan periode sebelumnya $\mathrm{b}+\alpha$ (Permintaan aktual periode sebelumnya - Peramalan periode sebelumnya)

$\mathrm{Ft}=\mathrm{F}_{\mathrm{t}-1}+\mathrm{a}\left(\mathrm{A}_{\mathrm{t}-1}-\mathrm{F}_{\mathrm{t}-1}\right)$

Dimana:

Ft $\quad=$ Nilai peramalan yang baru

Ft-1 = nilai peramalan periode sebelumnya

a $\quad=$ Konstanta pemulusan untuk data $(0<\mathrm{a}<1)$

At-1 = nilai permintaan actual periode sebelumnya

Diketahui :

$\begin{array}{llll}\text { a) } \quad \text { Bulan Desember 2017 } & =(0,30)(70735)+(0,70)(70735) & =70735 \\ \text { b) } \quad \text { Bulan Januari 2018 } & =(0,30)(69015)+(0,70)(70735) & =70219 \\ \text { c) } \quad \text { Bulan Februari 2018 } & =(0,30)(119342)+(0,70)(70219) & =84955,9 \\ \text { d) } \quad \text { Bulan Maret 2018 } & =(0,30)(61608)+(0,70)(84955,9) & =77951,53 \\ \text { e) } \quad \text { Bulan April 2018 } & =(0,30)(83468)+(0,70)(77951,53) & =79606,47 \\ \text { f) } & \text { Bulan Mei 2018 } & =(0,30)(62738)+(0,70)(79606,47) & =74545,93 \\ \text { g) } & \text { Bulan Juni 2018 } & =(0,30)(78498)+(0,70)(74545,93) & =75731,55 \\ \text { h) } \quad \text { Bulan Juli 2018 } & =(0,30)(79038)+(0,70)(75731,55) & =76723,49 \\ \text { i) } & \text { Bulan Agustus 2018 } & =(0,30)(91786)+(0,70)(76723,49) & =81242,24 \\ \text { j) } \quad \text { Bulan September 2018 } & =(0,30)(92458)+(0,70)(81242,24) & =84606,97\end{array}$




\section{KAIZEN : MANAGEMENT SYSTEMS \& INDUSTRIAL ENGINEERING JOURNAL VOL. 2 NO. 1 TEKNIK INDUSTRI UNIVERSITAS PGRI MADIUN}

Berdasarkan hitungan ramalan menggunakan exponential smoothing alpha sebesar 0,30 pada bulan September (no 13) terjadi permintaan sebesar 84606,97 produk pipa baja galvanis, permintaan tersebut akan menjadi perhitungan dalam pengolahan data persediaan bahan baku perhitungan EOQ.

4. MAD , MSE, MAPE

Berdasarkan dari metode forecasting, moving average, weighted moving average dan exponential smoothing dapat diketahui nilai error dari per masing-masing metode. Berikut ini merupakan nilai total error yang akan dijelaskan pada Tabel 5 dibawah ini.

Tabel 5. Hasil Perhitungan Nilai Error

\begin{tabular}{|c|c|c|c|c|}
\hline No & Error & $\begin{array}{c}\text { Moving Average } \\
\text { 3 Bulanan }\end{array}$ & $\begin{array}{c}\text { Weighted Moving } \\
\text { Average Bobot 3 }\end{array}$ & $\begin{array}{c}\text { Exponential } \\
\text { Smoothing } \boldsymbol{\alpha} \text { 0,30 }\end{array}$ \\
\hline 1 & $M A D$ & 16442,96 & 16941,27 & 14456,96 \\
\hline 2 & $M S E$ & 415672600 & 516513700 & 406150300 \\
\hline 3 & $M A P E$ & .21 & .21 & .17 \\
\hline \multicolumn{2}{|r|}{ Total } & 415689043,17 & 516530641,48 & 406164757,13 \\
\hline
\end{tabular}

Dapat diketahui bahwa nilai error terkecil terdapat pada metode forecasting exponential smoothing 3 bulanan. Dengan permintaan sebesar $\mathbf{8 4 6 0 6 , 9 7}$ produk pipa baja galvanis jadi, data ini nantinya akan menjadi tahap persediaan bahan baku dengan menggunakan metode $E O Q$.

5. Pembelian dan Pemakaian Bahan Baku

Pembelian bahan baku yang dilakukan PT. Angkasa Raya Steel 48 kali dalam 1 Tahun atau 4 kali dalam 1 Bulan. Selama pemakaian bahan baku tidak selalu sama karena ditentukan oleh pemakaian bahan baku setiap harinya dan jumlah permintaan pasar. Berikut ini merupakan data pembelian dan pemakaian bahan baku yang ada di PT. Angkasa Raya Steel selama 2016 - 2018. Berdasarkan Tabel 6. menunjukkan bahwa pembelian dan pemakaian menunjukkan terjadi adanya sisa bahan baku selama per tahun 2016 - 2018.

Tabel 6. Pembelian dan Pemakaian Bahan Baku Coil

\begin{tabular}{|c|c|c|c|}
\hline Tahun & Pembelian bahan baku & Pemakaian & Sisa Bahan Baku \\
\hline 2016 Sept - Aug 2017 & 4800 ton & 4740 ton & 60 ton \\
\hline 2017 Sept- Aug 2018 & 5040 ton & 4950 ton & 90 ton \\
\hline
\end{tabular}

6. Harga Beli Bahan Baku

Berikut ini merupakan daftar harga pembelian bahan baku coil di PT. Angkasa Raya Steel selama tahun 20162018. Tabel 7. diatas menunjukkan bahwa harga bahan baku coil tidak sama, setiap Tahunnya terus mengalami peningkatan.

Tabel 7. Harga Beli Bahan Baku coil

\begin{tabular}{|c|c|c|}
\hline No. & \multicolumn{2}{|c|}{ Harga Bahan Baku } \\
\hline 1 & 2016 & 220.000 \\
\hline 2 & 2017 & 230.000 \\
\hline 3 & 2018 & 250.000 \\
\hline
\end{tabular}

7. Biaya penyimpanan

Dengan adanya pembelian bahan baku coil akan menimbulkan biaya penyimpanan. PT. Angkasa Raya Steel menetapkan persentase biaya penyimpanan per tahun. Berikut merupakan biaya penyimpanan bahan baku coil. Tabel 8. Menunjukkan biaya penyimpanan bahan baku coil di PT. Angkasa Raya Steel. Berdasarkan penetapan kebijakan PT. Angkasa Raya Steel menetapkan pada bulan September 2017 sampai Agustus 2018 biaya simpan sebesar 0,05 meliputi biaya penyimpanan bahan baku dan produk jadi.

Tabel 8. Biaya Penyimpanan

\begin{tabular}{|c|c|}
\hline Jenis Biaya & Pipa Baja Galvanis \\
\hline Biaya Pemeliharaan Bahan & 150.000 \\
\hline Jumlah & 150.000 \\
\hline
\end{tabular}

Copyright (C) 2019, Kaizen : Management Systems \& Industrial Engineering Journal ISSN 15222-96806 (print), ISSN $155222-95973$ (online) 


\section{KAIZEN : MANAGEMENT SYSTEMS \& INDUSTRIAL ENGINEERING JOURNAL VOL. 2 NO. 1 TEKNIK INDUSTRI UNIVERSITAS PGRI MADIUN}

8. Biaya Pemesanan

Tabel 9. merupakan data biaya pemesanan yang ada PT. Angkasa Raya Steel pada tahun 2016-2018. Berdasarkan biaya pemesanan setiap tahunnya tidak sama dikarenakan peningkatan biaya setiap tahun.

Tabel 9. Biaya Pemesanan Bahan Baku Coil Tahun 2016-2018.

\begin{tabular}{|c|c|c|}
\hline Tahun & Jenis biaya & Jumlah Rp. \\
\hline \multirow{3}{*}{2016} & Biaya Telepon & $30.000,00$ \\
\hline & Biaya Bongkar & $580.000,00$ \\
\hline & Total & $610.000,00$ \\
\hline \multirow{3}{*}{2017} & Biaya Telepon & $50.000,00$ \\
\hline & Biaya Bongkar & $650.000,00$ \\
\hline & Total & $700.000,00$ \\
\hline \multirow{3}{*}{2018} & Biaya Telepon & $80.000,00$ \\
\hline & Biaya Bongkar & $800.000,00$ \\
\hline & Total & $880.000,00$ \\
\hline
\end{tabular}

9. Persediaan pengaman (safety stock)

Perhitungan persediaan pengaman untuk periode selanjutnya tahun 2018 diawali dengan menghitung satandard deviasi $(\sigma)$. Setelah diketahui jumlah permintaan pipa baja galvanis dan standar deviasi dari total permintaan, mka selanjutnya akan dihitung persediaan pengaman (ss).

$\sigma=\frac{\sum_{\mathrm{i}=1}^{\mathrm{n}}\left(\mathrm{x}_{\mathrm{i}}-\overline{\mathrm{x}}\right)^{2}}{\mathrm{n}-1}$

$\sigma=\frac{517140640}{11}$

$\sigma=47012785$ ton

$$
\begin{aligned}
& \mathrm{ss}=\mathrm{Z} \times \mathrm{SD} \times \sqrt{1} \\
& \mathrm{ss}=1,65 \times 47012785 \times \sqrt{7} \\
& \mathrm{ss}=205233827
\end{aligned}
$$

10. Ukuran dan frekuensi pemesanan dengan EOQ

Tabel 10. menunjukkan bahwa metode exponential smoothing 3 bulan digunakan dalam menentukan persediaan bahan baku. Pada studi kasus di PT. Angkasa Raya Steel pada tahun 2016-2018 dihitung ukuran

\begin{tabular}{|c|c|c|c|c|c|c|c|}
\hline No & Bulan & Permintaan & $\begin{array}{l}\text { Exponential } \\
\text { Smoothing }\end{array}$ & No & Bulan & Permintaan & $\begin{array}{l}\text { Exponential } \\
\text { Smoothing }\end{array}$ \\
\hline 1 & September 2017 & 87857 & - & 7 & Maret 2018 & 83468 & 77951,53 \\
\hline 2 & Oktober 2017 & 93457 & - & 8 & April 2018 & 62738 & 79606,47 \\
\hline 3 & November 2017 & 70735 & - & 9 & Mei 2018 & 78498 & 74545,93 \\
\hline 4 & Desember 2017 & 69015 & 70735 & 10 & Juni 2018 & 79038 & 75731,55 \\
\hline 5 & Januari 2018 & 119342 & 70219 & 11 & Juli 2018 & 91786 & 76723,49 \\
\hline 6 & Februari 2018 & 61608 & 84955,9 & 12 & Agustus 2018 & 92458 & 81242,24 \\
\hline \multicolumn{6}{|c|}{ Total } & 990000 & 691711,11 \\
\hline \multicolumn{6}{|c|}{ Average } & 82500 & 57642,5925 \\
\hline
\end{tabular}
pemesanan (EOQ) dan frekuensi pemesanan (f).

Tabel 10. Data Persediaan

$$
\begin{array}{ll}
\mathrm{EOQ}=\frac{\sqrt{2 \mathrm{Ds}}}{\mathrm{H}} & \mathrm{f}=\frac{\mathrm{D}}{\mathrm{Q}} \\
\mathrm{EOQ}=\frac{\sqrt{2 \times \operatorname{Rp} 880,000 \times \mathrm{Rp} \mathrm{691711,11}}}{\mathrm{Rp} 150,000 \times 0,03} & \mathrm{f}=\frac{691711,11}{12740} \\
\mathrm{EOQ}=\sqrt{\frac{1217411553,6}{7,5}} & \mathrm{f}=54 \mathrm{kali} \\
\mathrm{EOQ}=12,740 \text { ton } &
\end{array}
$$

11. Biaya Persediaan dengan EOQ

Biaya Persediaan (BP) digunakan untuk menghitung biaya pipa baja galvanis untuk 1 tahun ke depan. Biaya dihitung melalui penjumlahan Biaya Pemesanan (BR) dengan Biaya Penyimpanan (BS). 


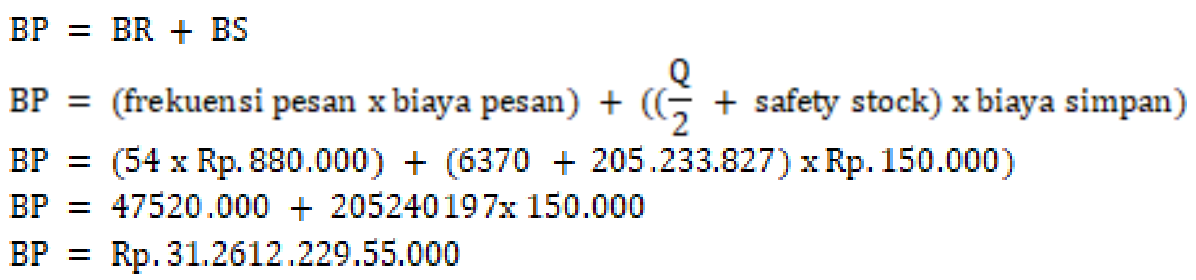

Hasil dari perhitungan biaya persediaan dengan menggunakan metode EOQ untuk produk pipa baja galvanis sebesar Rp. 31.2612.229.55.000

12. Waktu pemesanan kembali (Reorder Point)

Adapun perhitungan waktu pemesanan kembali (ROP) untuk produk pipa baja galvanis adalah sebagai berikut:

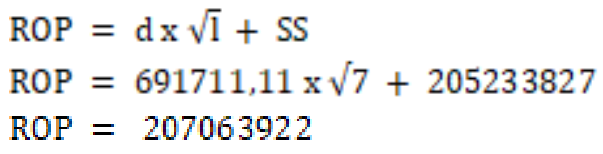

13. Persediaan maksimum (maximum inventory)

$$
\begin{aligned}
& \text { MI }=\text { SS }+ \text { EOQ } \\
& \text { MI }=205.233 .827+12740 \\
& \text { MI }=205246567
\end{aligned}
$$

\section{Simpulan}

Berdasarkan hasil penelitian yang dilakukan dapat diambil kesimpulan adalah perhitungan peramalan dengan menggunakan 3 metode menghasilkan 1 metode dengan jumlah SEE terkecil yaitu pada metode Exponential Smoothing dg a 0,30 dengan nilai 84606,97. Setelah diketahui bahwa untuk meramalkan bulan September 2018 metode exponential smoothing 3 bulan dipilih sebagai acuan dalam persediaan bahan baku dikarenakan mempunyai nilai error terkecil dengan nilai 406164757,13. Berdasarkan hasil pengendalian persediaan dengan metode EOQ dapat diketahui dengan menggunaan metode $E O Q$, jika PT. Angkasaaya Steel menggunakan metode $E O Q$ dapat menghemat biaya sebesar Rp 31.261.22.955.000 per Tahun

\section{Daftar Pustaka}

[1] J. Heizer and B. Render, Operations Management. Jakarta: Salemba empat, 2011.

[2] A. Taufiq and A. Slamet, "Pengendalian Persediaan Bahan Baku dengan Metode Economic Order Quantity (EOQ) pada Salsa Bakery Jepara," Manag. Anal. J., vol. 3, no. 1, pp. 1-6, 2014.

[3] M. M. Hanafi, Manajemen Keuangan. Yogyakarta: BPPE, 2004.

[4] E. H. A. Fajrin and A. Slamet, "Analisis Pengendalian Pesediaan Bahan Baku dengan Menggunakan Metode Economic Order Quantity (EOQ) pada Perusahaan Roti Bonansa," Manag. Anal. J., vol. 5, no. 4, pp. 289298, 2016.

[5] J. Heizer and R. Barry, Operations Management. Jakarta: Salemba Empat, 2014.

[6] S. Assauri, Manajemen Produksi dan Operasi. Jakarta: Lembaga Penerbit Fakultas Ekonomi Universitas Indonesia, 2008.

[7] E. Ostertagova and O. Ostertag, "Forecsting Using Simple Exponential Smoothing Method," J. Compil. Acta Electrotech. Inform., vol. 3, 12AD. 